\title{
Vertical steam generators for VVER NPPs*
}

\author{
Mikhail Yu. Egorov ${ }^{1}$ \\ 1 Peter the Great St. Petersburg Polytechnic University, 29 Polytechnicheskaya st., Saint Petersburg, 195251 Russia \\ Corresponding author: Mikhail Yu.Egorov (mikhail.yu.egorov@gmail.com)
}

Academic editor: Boris Balakin • Received 12 November 2018 • Accepted 11 February 2019 • Published 30 March 2019

Citation: Egorov MYu (2019) Vertical steam generators for VVER NPPs. Nuclear Energy and Technology 5(1): 31-38. https://doi. org/10.3897/nucet.5.33980

\begin{abstract}
Steam generators for NPPs are the important large-sized metal consuming equipment of nuclear power installations. Efficiency of steam generator operation determines the overall service life of the whole nuclear facility.

The main aim of the current study is to analyze advantages and shortcomings of horizontal and vertical types of steam generator design. This analysis is aimed at the development of recommendations for designing advanced steam generators for future Russian units of NPPs with VVER reactors of increased power.

Design solutions and fifty-year experience of operation of 400 steam generators of horizontal type accepted in Russia and of vertical type applied by Westinghouse, Combustion Engineering, Siemens, Mitsubishi, Doosan were analyzed within the framework of the present study. Advantages and drawbacks of both types of equipment determining the development of conditions of the operating processes were also identified and systematized.

Currently NPPs equipped with VVER are characterized with extended surface area of containment shells due to the application of four-loop design configuration and horizontal-type steam generators. It was established that steam generator equipment of horizontal type is characterized by such inherent disadvantages of design, technological and operational nature as the following: 1) small height and volume of the vapor space above the evaporation surface reducing separation capabilities and the capacity of the equipment as a whole; 2) impossibility of organizing separate single-phase pre-boiling section. Because of the above, horizontal steam generators with dimensions permissible for railroad transportation and, for VVER-1200 with reactor vessel diameter equal to $5 \mathrm{~m}$, by water transport as well, have exhausted the possibilities for further significant increase of the per unit electric power.

The demonstrated advantages of vertical-type steam generators were as follows: 1) absence of stagnant zones within the second cooling circuit, and, consequently, of hold-ups in them; 2) uniformity of heat absorption efficiency of the heating surface ensuring, as well, improved conditions for moisture separation; 3) high degree of moisture removal from steam-water mixture due to the combination of moisture separating elements of chevron and swirl-vane types; 4) increased temperature drop with parameters of generated steam elevated by $0.3-0.4 \mathrm{MPa}$.

Conclusion was made on the advisability of introduction of steam generators with vertical-type layout in the Russian nuclear power generation. Practical tasks that need to be addressed in order to ensure introduction of vertical steam generators at NPPs with high-power VVER reactors were formulated.
\end{abstract}

\section{Keywords}

Vertical type steam generator; horizontal type steam generator; light water nuclear reactor; natural circulation; variable cyclic thermal stresses; pre-boiling section; heat exchange; steam-water mixture; temperature difference; separators of chevron and swirl-vane type; containment; the four-loop layout.

* Russian text published: Izvestiya vuzov. Yadernaya Energetika (ISSN 0204-3327), 2018, n. 3, pp. 88-99.

Copyright Egorov MYu. This is an open access article distributed under the terms of the Creative Commons Attribution License (CC-BY 4.0), which permits unrestricted use, distribution, and reproduction in any medium, provided the original author and source are credited. 


\section{Introduction}

Steam generator is one of the most important elements of nuclear power installation. Its purpose is to produce water steam - the working medium of the power generation cycle. Steam production is associated with the following complex processes (Rassokhin 1987, Fedorov et al. 1992):

- Transfer of heat from heating coolant of the NPP primary cooling circuit to the heated water of the secondary cooling circuit;

- Conversion of thus heated water into water steam;

- Circulation of steam-water mixture;

- Separation of water from steam.

Significant part of emergency shut-downs of NPPs are caused, in particular, by failures of steam generators (Trunov et al. 2006, Trunov et al. 2011).

Steam generator for VVER-1000 power unit (Fig. 1) is a large-sized equipment with vessel length of $14.5 \mathrm{~m}$ and diameter up to $4.2-4.3 \mathrm{~m}$. Russian NPPs equipped with VVER-1000 reactors have four-loop cooling configuration, i.e. each power unit incorporates four steam generators occupying significant space inside the containment shell of the reactor unit (Fig. 2). The larger are the dimensions of the containment shell the higher is its cost and time expended for its construction. Containment shell must be strong enough, i.e. it must be capable to withstand excess pressure of steam-water mixture in case of accident accompanied with failure of pressurization in the primary cooling circuit. The larger is the diameter of the shell which is a pressurized vessel, the more difficult it becomes to ensure its strength. Therefore, decrease of containment shell diameter attains significant importance.

Comparative analysis of contemporary design of steam generators and earlier design configurations presented, for instance, in (Lukasevich et al. 2004), demonstrated that during the period of development of "large-scale" nuclear power generation industry beginning from the time of its initiation (beginning of the 1960-ies), design layouts of steam generators remain practically unchanged, because one can hardly expect from surface type heat exchange equipment based on transfer of heat from one medium to another one through walls of metal tubes design solutions different from the conventional ones, namely tube and shell heat exchangers.

The positive side of such conservatism is associated with the fact that the design solutions supported by several decades of practical application in the process of development of different technical fields including power generation, ship building and chemical technologies, allow obtaining in many cases durable and reliable equipment.

The negative side of such conservatism amounts to the obtaining equipment with excessive mass and, consequently, increased metal consumption and, in separate cases, equipment which is not sufficiently reliable when unfavorable processes must be dealt with in the process of operation of such equipment.

Let us analyze the advantages and drawbacks of design solutions and organization of working processes in steam generators for the purpose of search for the potential for enhancement of per unit power of power units of nuclear power installations equipped with light water nuclear power reactors and enhancement of parameters of the generated steam.

\section{Steam generators of horizontal type}

Steam generators of horizontal type are used on NPPs with VVER reactors from the moment of initiation of development of nuclear power generation (Dmitriev et al. 2013).

\section{Advantages of the design}

1. The design is relatively straightforward and simple: manufacturing of chevron-type separation devices is simpler as compared with swirl-vane separators.

2. Dimensions allow railroad transportation of the equipment.

3. Absence of thick flat tube sheets. Heating medium headers have cylindrical shape.

The first horizontal steam generators were applied on relatively low-power nuclear installations with low parameters of steam which were intended for different process applications (not power generation).

Starting from 1964 steam generators of horizontal type were applied on power units of the Novovoronezh NPP with per unit electric power of 210, 365 and $440 \mathrm{MW}$. Operation of this equipment proved to be reliable enough.

\section{Shortcomings of the design revealed in the process of operation of Russian NPPs}

Fractures in the header structures took place already during the initial period of operation of VVER-440 power units. Fracturing was caused by the intersection of the level of water in the secondary cooling circuit with hotter header wall. In case of fluctuation of water level inevitable on NPP variable cyclic thermal stresses developed within the header wall. This problem was successfully resolved by sealing voids between the steam generator partitions protecting the header wall in the region of water level fluctuations from direct contact with water of the secondary cooling circuit. Prior to that, inadequate sealing of the voids resulted in the contact between the relatively cool water with relatively hot header walls.

Horizontal PG-1000 steam generators were introduced during the subsequent period of operation initially of Unit 5 of the Novovoronezh NPP followed by other NPP 


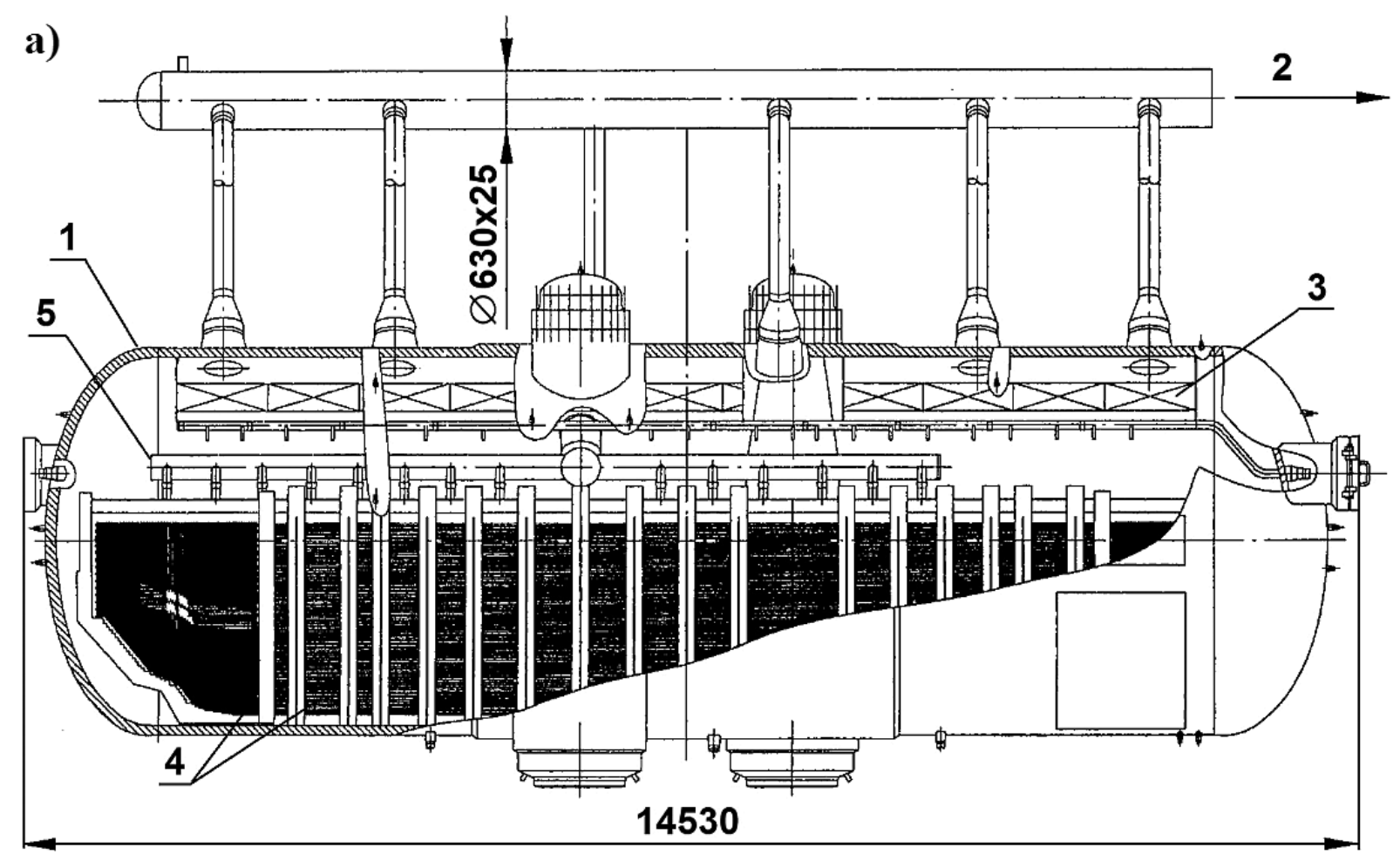

b)

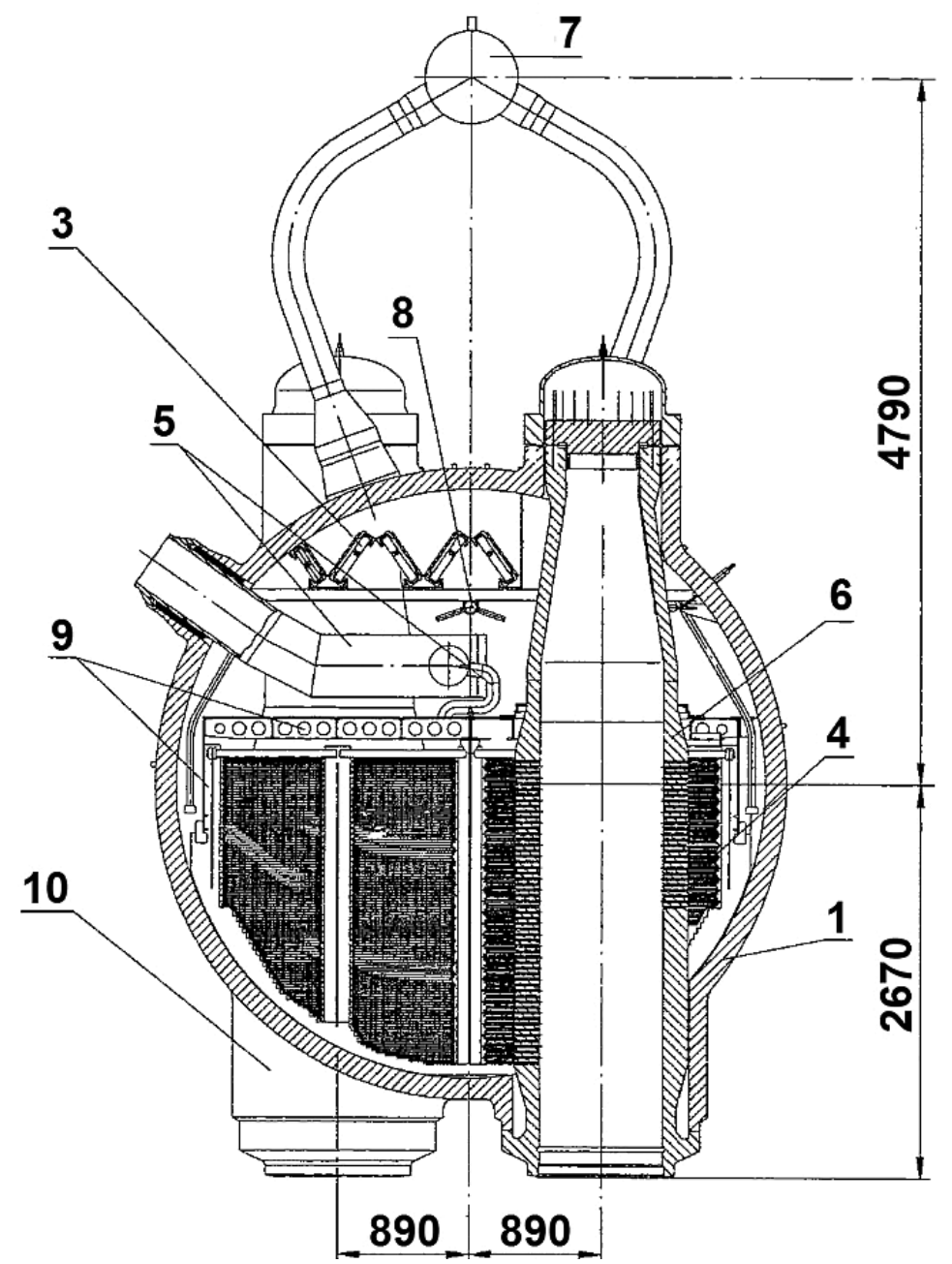

Figure 1. Horizontal type steam generator for VVER -1000 (Unit 5 Novovoronezh NPP): a) - longitudinal section, b) - cross-section, 1 - vessel; 2 - steam outlet; 3 - chevrons of the separator unit; 4 - heat exchange tube bundle; 5 - supply of feed water; 6 outlet header; 7 - steam header; 8 - supply of auxiliary feed water; 9 - tube bundle support; 10 - inlet header 


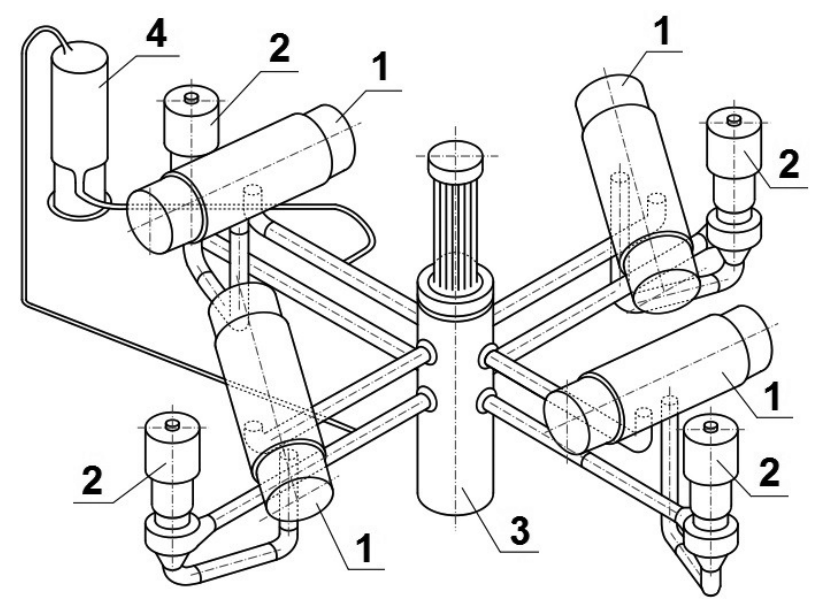

Figure 2. Three-dimensional layout of VVER-1000 NPP: 1 steam generator; 2 - circulation pump; 3 - reactor; 4 - pressurizer

power units. In the course of transition from power installation with VVER-440 to significantly higher electric power (1000 MW) design of horizontal steam generators reached their limiting thermal hydraulic characteristics.

Besides the above considerations, external dimensions of steam generators are limited by the requirements of their transportation by railroad transport. Therefore, it was necessary to increase specific thermal and steam loads by more than two times and to reduce factual inventories as refers to water level in the secondary cooling circuit and the emergency reserve of this boiler water in the shell in the case of accident of the "feed water supply break" type. These restrictions initiated certain negative consequences - 45 steam generators had to be replaced on the Novovoronezh, South Ukraine, Zaporozhye and Balakovo NPPs (Mahutov et al. 2003). The main cause which prompted the necessity of replacement of steam generators was the development of fractures in the walls of "cold" headers collecting flows of heating medium from heat exchange tubes at the outlet of the equipment. When water levels in the secondary cooling circuit fluctuated in case of transients accompanied with variation of pressure and flow rates of the heat transferring medium, lowering of the level caused by faulty automation or human errors (Bazhanov et al. 1988), situations developed when tubes in upper levels of the heating surface appeared to be above the level of water, heat transferring medium was not cooled in the tubes and "cold" header was becoming "hot" on certain parts of its surface area. This process was non-stationary because of instability both of the water level, and of the nature of boiling process (Sinitsyn et al. 2013, Kirillov et al. 2013, Tsvetkov and Grigoriev 2011) (transition from bubble boiling to film boiling and back) in the vicinity of outer wall of the "cold" header, in connection with which fluctuating thermal stresses developed in the parts of the wall in question.

Designers (OKB "Gidropress") and manufacturers (Machine-Building Plant of Podolsk) of horizontal steam generators undertook significant efforts for enhancing reliability of the equipment including the following:
- Replacement of header materials;

- Increased spacing of partitions between the holes for tubes in the headers within the critical area;

- Rejection of explosive tube expansion which may cause additional stresses in the material.

Advancement of design of horizontal steam generators produced positive results. Currently search for design solutions aimed at the enhancement of intensity of heat exchange processes both in the equipment of NPP as a whole (Aksenov and Egorov 2017a, Aksenov and Egorov 2016) and in NPP steam generators (Gortyshov et al. 2009, Aksenov and Egorov 2017b) is ongoing.

Nevertheless, principal shortcomings of the concept of steam generator of horizontal type and, first of all, impossibility of enhancement of per unit electric power of the equipment in excess of $50 \mathrm{MW}$, remain. This results in the situation when configurations of reactor facilities with horizontal steam generators requiring significant area under the containment shell of the primary cooling circuit are still used in the design of modern Russian VVER NPPs.

\section{Steam generators of vertical type}

The design concept of steam generators with vertical spatial orientation of vessel for NPP equipped with light water reactors (PWR) is well known. It was implemented on NPPs in different countries beginning from the middle of 1950-ies by Westinghouse, Combustion Engineering and other companies (Kolev 2015). Working process in the vertical steam generator is achieved by repetitive natural circulation of steam-water mixture inside the vessel and in the annulus under significant dynamic pressure (due to the height of the equipment). This leads to high rate of circulation of water-steam mixture and to high steam quality in the mixture at the outlet from the bundle of tubes conducting heating medium, i.e. water of the NPP primary cooling circuit. Possibility emerges as the result to achieve in one reactor installation higher electric power equal to at least $500 \mathrm{MW}$.

Considerable experience of operation of vertical steam generators on foreign NPPs demonstrated both their advantages and shortcomings. Sketch of steam generator manufactured by Westinghouse Electric Corporation (USA) is presented in Figure 3.

\section{Shortcomings of the design revealed in the process of operation on foreign NPPs}

The main disadvantages of design of steam generators of vertical type were manifested in the form of massive damages up to the development of penetrating fractures in the tubes. The damages took place due to hideout corrosion in the region of flat bottom tube sheets, as well as due to deformation, corrosion and wear in the places where holdups of solid impurities were accumulated in the grids spacing tube bundles. This resulted 


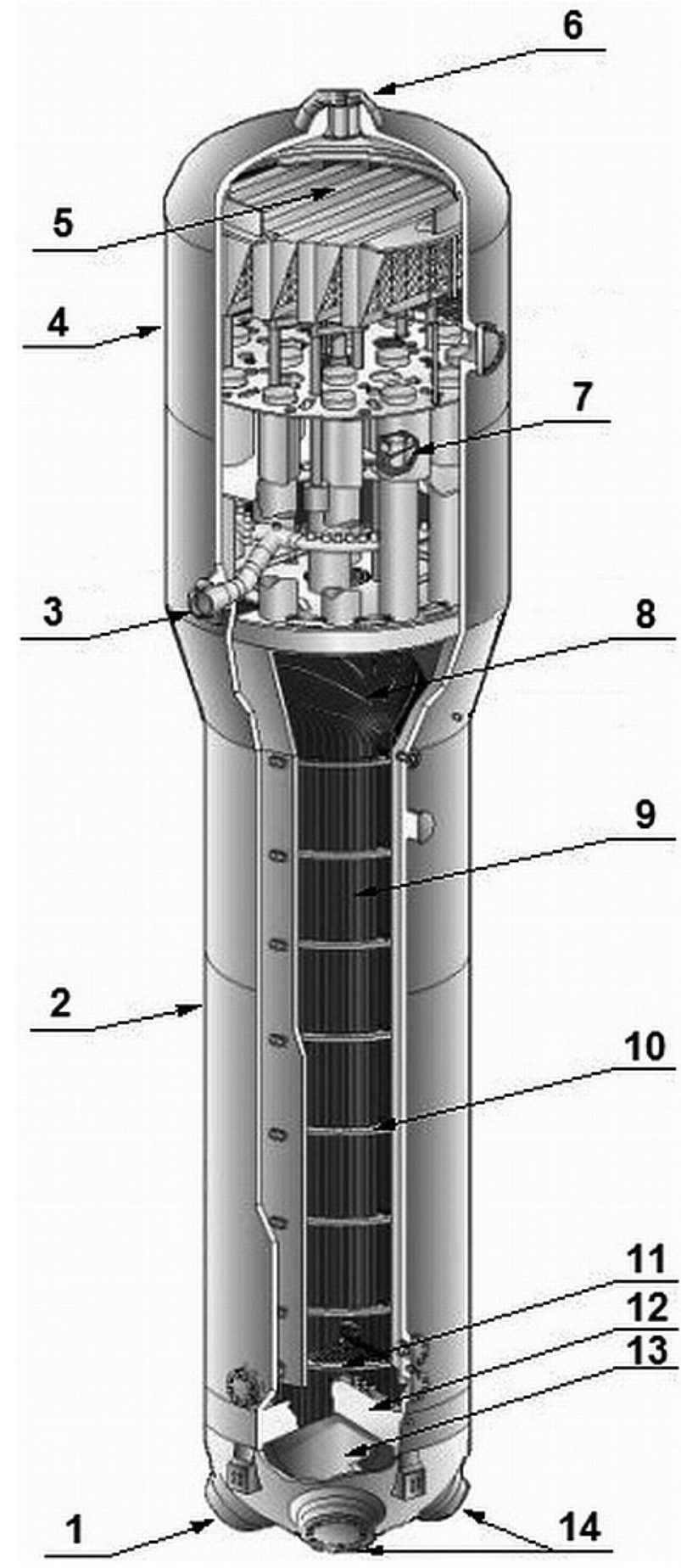

Figure 3. Vertical type steam generator manufactured by Westinghouse Electric Corporation (USA): 1 - inlet of coolant of the primary cooling circuit; 2 - bottom part of the vessel; 3 - feed water inlet; 4 - upper part of the vessel; 5 - second stage of moisture separation; 6 - steam outlet; 7 - first stage of moisture separation (swirl-vane); 8 - anti-vibration tube supports; 9 - tube bundles; 10 - spacer grids; 11 - divider plate for flow distribution; 12 - tube sheet; 13 - separating partition; 14 - outlet of coolant of the primary cooling circuit

in significant financial losses due to the replacement of about 300 items of equipment on the operated NPPs (Trunov et al. 2005).
Steam generators of vertical type exist in Russia only as design documents (Sudakov et al. 2012). This obstacle does not allow comprehensive enough and objective comparison of the horizontal and vertical types of the equipment because of the absence of first-hand experience of operation of vertical steam generators.

\section{Advantages of the design}

Vertical steam generators which must be developed taking into consideration the experience of operation on foreign NPPs, including negative experience, possess the following advantages as compared to horizontal steam generators.

1. Improved arrangement of components under the containment shell result in the saving of materials and reduction of volumes of construction operations. Four horizontal steam generators installed under the containment shell in the modern VVER-1000 reactor installations occupy four times more area than four and, even more so, than two or three vertical steam generators with higher per unit capacity.

2. Absence of slurry holdups in stagnation zones along the secondary cooling circuit. There are no such zones in vertical steam generators, while they are present in horizontal steam generators in the region of lower tube rows.

3. Possibility to have tubes of the same length and uniformity of open area for penetration of steam-water mixture flow over the cross-section of the equipment due to the bend of platen of heat exchange surface along the involute curve result in the uniformity of heat absorption efficiency of the heating surface and improves operational conditions of the separator.

Experience of manufacturing platens made of $\mathrm{X} 18 \mathrm{H} 10 \mathrm{~T}$ austenitic steel has been accumulated in Russia (Sudakov et al. 2012).

Experimental studies of the two-phase flow structure (local concentrations of the light phase, phase velocities) using the air-water model of the platen with natural dimensions (along the height), measurements of heat transfer efficiency using the model with natural dimensions, testing hermiticity of the seal group of the heating medium header, testing the large-scale experimental section of the steam generator model were performed in the course of designing indigenous vertical steam generators. Studies of full-scale model of steam generator with thermal capacity equal to 5-10 MW equipped with platen under natural parameters were also planned to be implemented on the Balakovo NPP.

Additional investigation of thermal hydraulic processes both from the side of the coolant and the working medium are necessary.

4. Application of two-stage (chevron and swirl-vane) system for separation of moisture with higher degree of steam drying.

5. "Hot" upper and "cold" lower parts of the vertical cylindrical header of the heating medium do not intersect 
the level of water in the secondary cooling loop. Schematic drawing of steam generator with header fixation of tubes is shown in Figure 4. Header to which the bundle of heat exchanging tubes is attached is installed along the central axis of the device.

6. Design of vertical single-phase pre-boiling steam generator allows organizing the so-called separate section, i.e. the heat exchanger for heating feed water to saturation temperature (Agafonova et al. 2017). This allows increasing average temperature difference in the equipment (Fig. 5). Enhancement of parameters of the produced steam by $0.3-0.4 \mathrm{MPa}$ is achieved due to that. It is not possible to organize single-phase pre-boiling section in the horizontal steam generator because feed water is supplied to the upper part of the device and is mixed with boiler water generating steam-water mixture at saturation temperature.

\section{Conclusion}

The performed analysis of development of concepts of horizontal and vertical steam generators for NPPs with Russian designed VVER pressurized light water reactors and with foreign PWR reactors allows formulating the following conclusions.

1. Fifty years of experience of operation of hundreds of horizontal and vertical steam generators revealed both positive and negative sides of both types of steam generator design. Both types of steam generators have deficiencies which are difficult to overcome.

2. A number of shortcomings of design, technological and operational mode nature were revealed in the process of operation of horizontal steam generators. Most part of the revealed drawbacks were removed during modernization of the equipment. Modern horizontal steam generators are characterized by the following non-removable drawbacks:

- Small height and volume of steam space above the evaporation mirror reducing efficiency of gravitational separation and prohibiting installation of swirlvane separators between the perforated sheet and chevron-type separators thus reducing the capacity of the device (Trunov et al. 2008);

- Complexity of organization in the tube bundle between two vertical headers of separate pre-boiling section cooled down with "cold" feed water;

- Equipment of reactor installation with horizontal steam generators is inferior in terms of compactness as compared with vertical steam generators and requires arrangement of bulky and cost intensive containment shell.

3. Since the design features of horizontal steam generators restrict the potential of enhancement of capacity of the power unit and parameters of generated steam, which negatively affects the financial performance of the reactor installation, development of reliable indi-

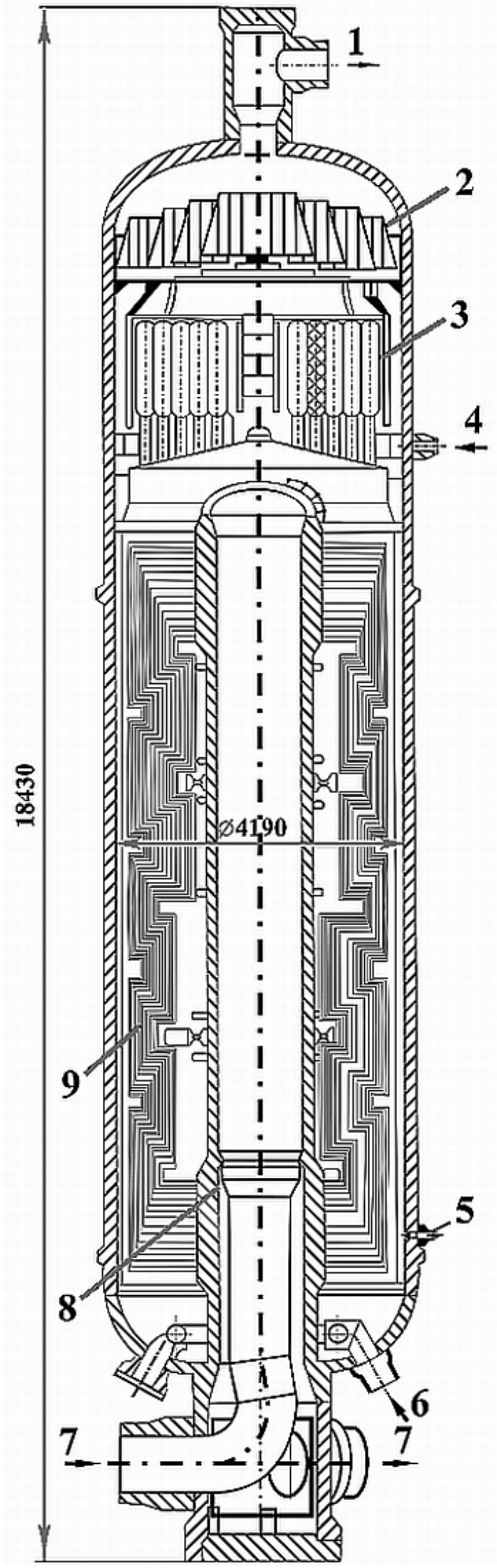

Figure 4. Steam generator with header tube fixation: 1 - steam; 2, 3 - chevron and swirl-vane separators; 4 - supply of auxiliary feed water; 5 - continuous blowdown nozzle; 6 - feed water; 7 - coolant; 8 - header; 9 - tube bundle platen 
genous vertical steam generator in the nearest future may become one of the priority directions of further development of nuclear machine-building industry.

The following is suggested for the purpose of implementation of vertical steam generators in the Russian nuclear power generation industry based on high-power VVER reactors:

- Conducting testing of large-scale models of vertical steam generators;

- Development of design project and testing the pilot steam generator device in the composition of NPP with VVER-1200 reactors.

Coordination of the above works can be performed by the group of experts representing design bureaus and research institutes and production facilities manufacturing heat exchange equipment for NPPs.

\section{References}

- Agafonova ND, Egorov MYu, Sergeev VV, Gotovsky MA, Kruglikov PA, Lebedev ME, Sudakov AV, Fedorovich ED, Fokin BS (2017) Intensification of heat and mass transfer processes in saturated steam generators of NPP with RWR as the means for improving efficiency and reliability. Atomnaya Energiya, 123(3): 128-132. [In Russian]

- Aksenov PL, Egorov MYu (2016) Intensification of heat transfer in the NPP equipment. Science week SPbSPU: Proc. of the Scient. Conf. with international participation. Institute of energy and transport systems. Part 1. Saint-Petersburg. Sankt-Petersburg Polytechnic University Publ.: 82-84. [In Russian]

- Aksenov PL, Egorov MYu (2017a) Analysis of methods for intensification of heat transfer in nuclear power plants. Energy systems: Collected reports of the II-nd International scientific-technical conference. Belgorod. Belgorod State Technological University Publ.: 251-257. [In Russian]

- Aksenov PL, Egorov MYu (2017b) Improving the design of the steam generator of a nuclear power plant using the ring Naka-current-turbulence. Energy systems: Collected reports of the II-nd International scientific-technical conference. Belgorod. Belgorod State Technological University Publ.: 258-264. [In Russian]

- Bazhanov VV, Vavilov AA, Davydov SS, Zalevsky PI, Ivanov VA (1988) Comparative analysis of dynamic characteristics of NPP with VVER-1000 and steam generators of various types. Energomashinostroenie, 4: 31-33. [In Russian]

- Dmitriev SM, Zverev DL, Bykh OA, Panov YuK, Sorokin NM, Farafonov VA (2013) Main equipment of NPP with freestanding thermal neutron reactors. Moscow. Mashinostroenie Publ., 415 pp. [In Russian]

- Fedorov LF, Titov VF, Rassokhin NG (1992) Steam generators of nuclear power plants. Saint-Petersburg - Moscow. Energoatomizdat Publ., 288 pp. [In Russian]

- Gortyshov YuF, Popov IA, Olimpiev VV, Shchelchkov AV, Kaskov SI (2009) Thermohydraulic efficiency of promising approaches to

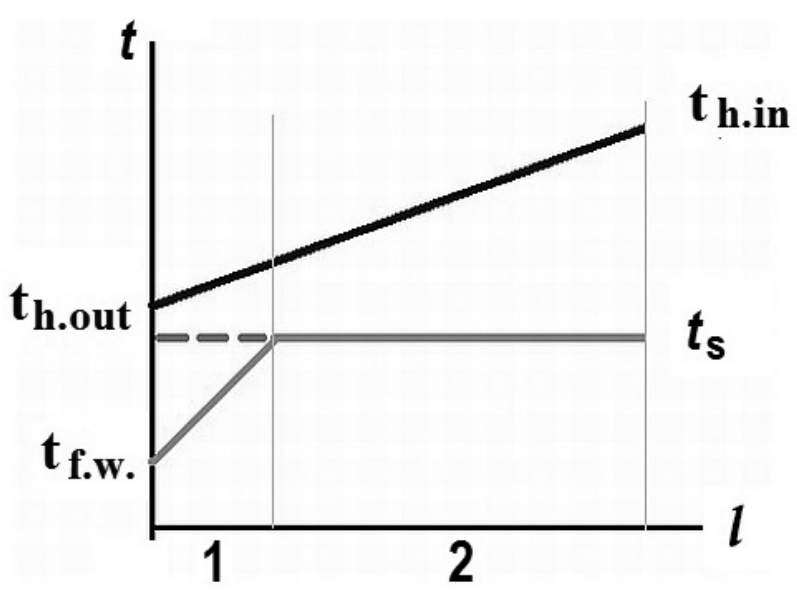

Figure 5. Layout of distribution of temperatures of the heating medium (coolant) $\left(t_{\mathrm{h}}\right)$ and medium of the secondary loop (feed water) $\left(t_{\text {f.w. }}\right)$ in the steam generator: 1 - separate pre-boiling section; 2 - evaporation section; $\left(t_{\mathrm{S}}\right)$; - - - - steam generator without separate pre-boiling section

intensification of heat transfer in the channels of heat transfer equipment. Intensification of heat transfer. Kazan. Center for Innovative Technologies Publ., 531 pp. [In Russian]

- Kirillov PL, Zhukov AV, Loginov NI (2013) Reference book on thermohydraulic calculations in nuclear power industry. Vol. 2: Nuclear reactors, heat exchangers, steam generators. Moscow. IzdAT Publ., 685 pp. [In Russian]

- Kolev NI (2015) Multiphase flow dynamics 5: nuclear thermal hydraulics. Switzerland: Springer International Publishing, $886 \mathrm{pp}$.

- Lukasevich BI, Trunov NB, Dragunov YuG, Davidenko SE (2004) Steam generators of VVER reactors for nuclear power plants. Moscow. Akademkniga Publ., 391 pp. [In Russian]

- Mahutov NA, Frolov KV, Dragunov YuG, Vasilchenko GS, Gadenin MM, Getman AF, Gorbatykh VP, Dranchenko BN, Zatsarinny VV, Karzov GP, Lukasevich BI, Makarenko IV, Makarenko LV, Mikhalev YuK, Razumovsky IA, Salin AN, Seleznev AV, Fomin AV, Shary NV (2003) The bearing capacity of steam generators of pressurized water reactors. Moscow. Nauka Publ., 440 pp. [In Russian]

- Rassokhin NG (1987) Steam generation equipment of nuclear power plants. Moscow. Energoatomizdat Publ., 384 pp. [In Russian]

- Sinitsyn AA, Karpov DF, Pavlov MV (2013) Theory and practice of heat transfer. Vologda. Vologda State Technical University Publ., 71 pp. [In Russian]

- Sudakov AV, Silin VV, Lebedev ME, Fokin BS, Danilin BK, Belenky MYa (2012) The prospects for the creation of a vertical steam generator with shirm heating surface for modern NPPs with VVERtype reactors. Theory and practice of modern science. Proc. of the VI-th International scientific-practical conference. Moscow, Spetskniga Publ.: 137-145. [In Russian]

- Trunov NB, Davidenko SE, Denisov VV (2005) Reliability and life span of tube bundles of steam generators of NPP with VVER. VANT. Ser: Obespechenie bezopasnosti AES. Reaktornye ustanovki s VVER, 9: 45-54. [In Russian] 
- Trunov NB, Denisov VV, Kharchenko SA, Lukasevich BI (2006) Consideration of field experience in developing new projects of steam generators for nuclear power stations equipped with VVER reactors. Thermal Engineering, 53(1): 37-42. https://doi.org/10.1134/ S004060150601006X

- Trunov NB, Lukasevich BI, Veselov DO, Dragunov YuG (2008) Steam generators - horizontal or vertical (which type should be used in nuclear power plants with VVER?). Atomic Energy, 105(3): 127135. https://doi.org/10.1007/s10512-008-9090-1

- Trunov NB, Ryzhov SB, Davidenko SE (2011) Horizontal steam generators: Problems and prospects. Thermal Engineering: 58(3): 179-183. https://doi.org/10.1134/S004060151103013X

- Tsvetkov FF, Grigoriev BA (2011) Heat and mass transfer. Moscow. Moscow Energy Institute Publ., 562 pp. [In Russian] 